\title{
A review of airflow rate estimation techniques for natural ventilation in buildings
}

Una revisión de las técnicas de estimación de la tasa de flujo de aire en edificios con ventilación natural

\author{
Miguel Chen-Austin (iD ${ }^{1,2 *}$, Dafni Mora (iD) ${ }^{1}$, Denis Bruneau (iD ${ }^{2,3}$, Alain Sempey (iD ${ }^{3}$ \\ ${ }^{1}$ Facultad de Ingeniería Mecánica, Universidad Tecnológica de Panamá. Avenida Universidad Tecnológica de Panamá, Vía \\ Puente Centenario. A. P. 0819-07289. Ancón, Panamá. \\ ${ }^{2}$ Groupe Recherche Environnement, Confort, Conception Architecturale et Urbaine -GRECCAU-. EA 7482. École National \\ Supérieure d'Architecture et de Paysage de Bordeaux - ENSAP Bordeaux-. 740 Cours de la Libération 33405 TALENCE \\ Cedex, France. \\ ${ }^{3}$ Institut de Mécanique et d'Ingénierie (I2M), UMR 5295, Université de Bordeaux, Arts et Métiers ParisTech. 351 Cours de \\ la Libération 33405 TALENCE Cedex, France.
}

\section{CITE THIS ARTICLE AS:}

M. Chein Austin, D. Mora, D.

Bruneau and A. Sempey. "A

review of airflow rate

estimation techniques for

natural ventilation in

buildings", no. 104, pp.

83-100, Jul-Sep 2022. [Online].

Available: https:

//www.doi.org/10.17533/

udea.redin. 20210849

\section{ARTICLE INFO:}

Received: June 24, 2020

Accepted: August 20, 2021

Available online: August 25,

2021

\section{KEYWORDS:}

Construction engineering; buildings; experimental methods; natural ventilation

Ingeniería de la construcción; edificios; métodos experimentales; ventilación natural
ABSTRACT: As natural ventilation involves local and global interactions, the estimation of these interactions can be performed by many approaches. Such approaches, rather more experimental and numerical than analytical, often require a great deal of instrumentation and equipment, which results in higher demands on project budget and funding. The present work is devoted to comprehending the natural ventilation concept, and to assess the existing experimental techniques already implemented for past researchers in the estimation of the ventilation airflow rate due to the wind and thermal buoyancy effects. A brief review of modeling techniques is also presented. This will provide a strong theoretical grasp of the natural ventilation process as part of the main elements in the thermal behavior of buildings. Ultimately, these bases are intended to help choose the most suitable techniques to estimate the natural ventilation airflow rate. The adequate benefit-to-budget technique appears to be the airtightness tests (blower door tests), since empirical Equations relating the airflow directly to the pressure difference in the building for both cases: infiltrations (openings closed) and openings opened, can be obtained. Also, the location of the leakages can be identified without complications, and this technique has the potential to estimate in situ the airflow capacity and friction characteristics of the openings.

RESUMEN: Como la ventilación natural implica interacciones locales y globales, la estimación de estas interacciones puede realizarse mediante muchos enfoques. Tales enfoques, mayormente experimentales y numéricos que analíticos, a menudo requieren alta instrumentación, lo que resulta en mayor demanda de financiamiento. El presente trabajo está dedicado a comprender el concepto de ventilación natural y a evaluar las técnicas experimentales existentes ya implementadas por investigadores anteriores en la estimación de la tasa de flujo de aire de ventilación, debido a los efectos del viento y el tiro térmico. También se presenta una breve revisión de las técnicas de modelado. Esto proporcionará una sólida comprensión teórica del proceso de ventilación natural como parte de los elementos principales en el comportamiento térmico de los edificios. Estas bases están destinadas a ayudar a elegir las técnicas más adecuadas para estimar la tasa de flujo de aire de ventilación natural. La técnica más adecuada de beneficio-presupuesto parece ser las pruebas de hermeticidad ya que las expresiones empíricas que relacionan el flujo de aire directamente con la diferencia de presión en el edificio para ambos casos: infiltraciones y aberturas abiertas, pueden ser adquiridas. Además, la ubicación de las fugas se puede identificar sin complicaciones, y esta técnica tiene el potencial de estimar la capacidad de flujo de aire in situ y las características de fricción de las aberturas.

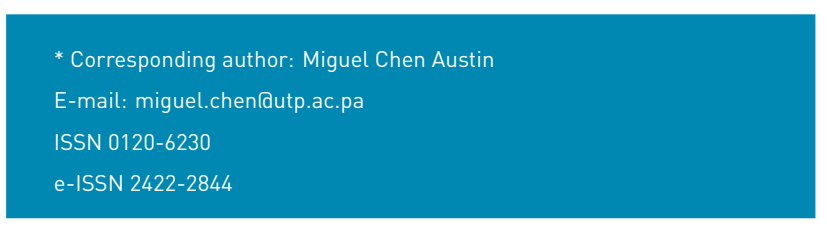




\section{Introduction}

Natural ventilation in buildings has been a subject exhaustively studied for more than 50 years. Still, the mechanics of such a physical problem has not been fully understood, despite the development of many descriptive experimental and numerical studies for airflow estimation coupled with heat transfer, to aid such an understanding. Many factors influence the adequate implementation of natural ventilation strategies regarding the occupant's comfort needs, and thus, affecting the energy consumption of the building. Among these factors, the behavior, knowledge, and tolerance of the occupants play an essential role.

Nowadays, natural ventilation continues to attract interest because of its benefits in terms of air renewal and cooling. Such benefits can provide a significant reduction in building energy consumption regarding location (latitude). In template latitudes, i.e., Europe, the implementation of natural ventilation in the summertime, results rather in an excellent strategy to reduce energy consumption for cooling purposes. On the other hand, in wintertime, natural ventilation serves rather to the renewable of stale and moist air resulting in an all-close strategy to avoid heat losses through air leakages, instead of using mechanical ventilation extraction. In very hot latitudes, i.e., the Middle East, the implementation of natural ventilation serves also rather air renewal purposes, since the outdoor air temperature presents a weak gap between daytime and nighttime and weak humidity levels. In such cases, the thermal mass of buildings plays a more critical role in the occupants' comfort. In tropical latitudes, with high humidity and temperatures with weak day-night fluctuations, ventilation together with appropriate thermal mass and insulation, significantly improve the thermal comfort [1, 2]. In such cases, bioclimatic strategies combined with natural ventilation, as to elevate the building floor about $3 \mathrm{~m}$ above the ground, can be useful to reduce the indoor moisture levels $[3,4]$.

Moreover, as the implementation of natural ventilation can reduce energy consumption related to the cooling process in buildings, usage recommendations are expected to be included in all energy regulation policies. This is the case of countries with operating super-efficient buildings as the nearly zero energy buildings (nZEB), and net-zero energy buildings (NZEB). Here, the management of natural ventilation can provide adequate results, utilizing automation systems regarding occupants' behavior. In this regard, the International Energy Agency (IEA) through the Energy in Buildings and Communities Programme (EBC), first devoted Annex 66 [5] to study and describe the occupants' behavior related to window opening (to profit from natural ventilation), and other related to energy consumption (appliances usage, lighting, among others). Second, in 2018 the IEA started working on Annex 79 [6] to provide solutions to occupants' preferences by considering the level of automation and control systems in the building.

As natural ventilation involves local and global interactions, being related all together by Navier-Stokes' equations, the estimation of these interactions can be performed by many local and global approaches. Such approaches, rather more experimental and numerical than analytical, often require a great deal of instrumentation and equipment for the former, which results in higher demands on project budget and funding. For the latter, depending on how detailed the analysis is wanted, the computation-time consumed to solve the equations becomes higher, which translates in the need for powerful computers, and thus, also increasing the demand for funding.

This work is devoted to comprehending the natural ventilation concept, and to assess the experimental and modeling techniques already implemented for past researchers, in the estimation of the ventilation airflow rate due to the wind and thermal buoyancy effects. This will provide a strong theoretical grasp of the natural ventilation process as part of the main elements in the thermal behavior of buildings. Ultimately, these bases are intended to help choose the most suitable techniques to estimate the natural ventilation airflow rate.

The structure of the present work is divided into three principal sections: (i) Natural ventilation in buildings, which includes the role of natural ventilation in buildings along with concept definitions and natural ventilation driving forces. (ii) Estimation of the natural ventilation airflow rate, which starts with defining the airflow capacity of openings, followed by $($ iii) experimental techniques and analytical/numerical techniques, finishing with a discussion intended to determine the most suitable experimental technique to estimate the airflow rate.

\section{Natural ventilation in buildings}

Natural ventilation is the process of renewing the air of a room by natural means by either from infiltrations (unavoidable) or window openings (on purpose). In general, there are three leading causes of air movements by natural means inside and around a building: $(i)$ wind effects, $($ ii) air temperature and solar radiation, and (iii) concentration of moisture and pollutants [7]. A schematic showing the relation and influence factors, among these three causes of air movements inside and around a building, is presented in Figure 1. Starting with the three leading causes of natural air movement, where the first two are normally known as the natural ventilation is driven 


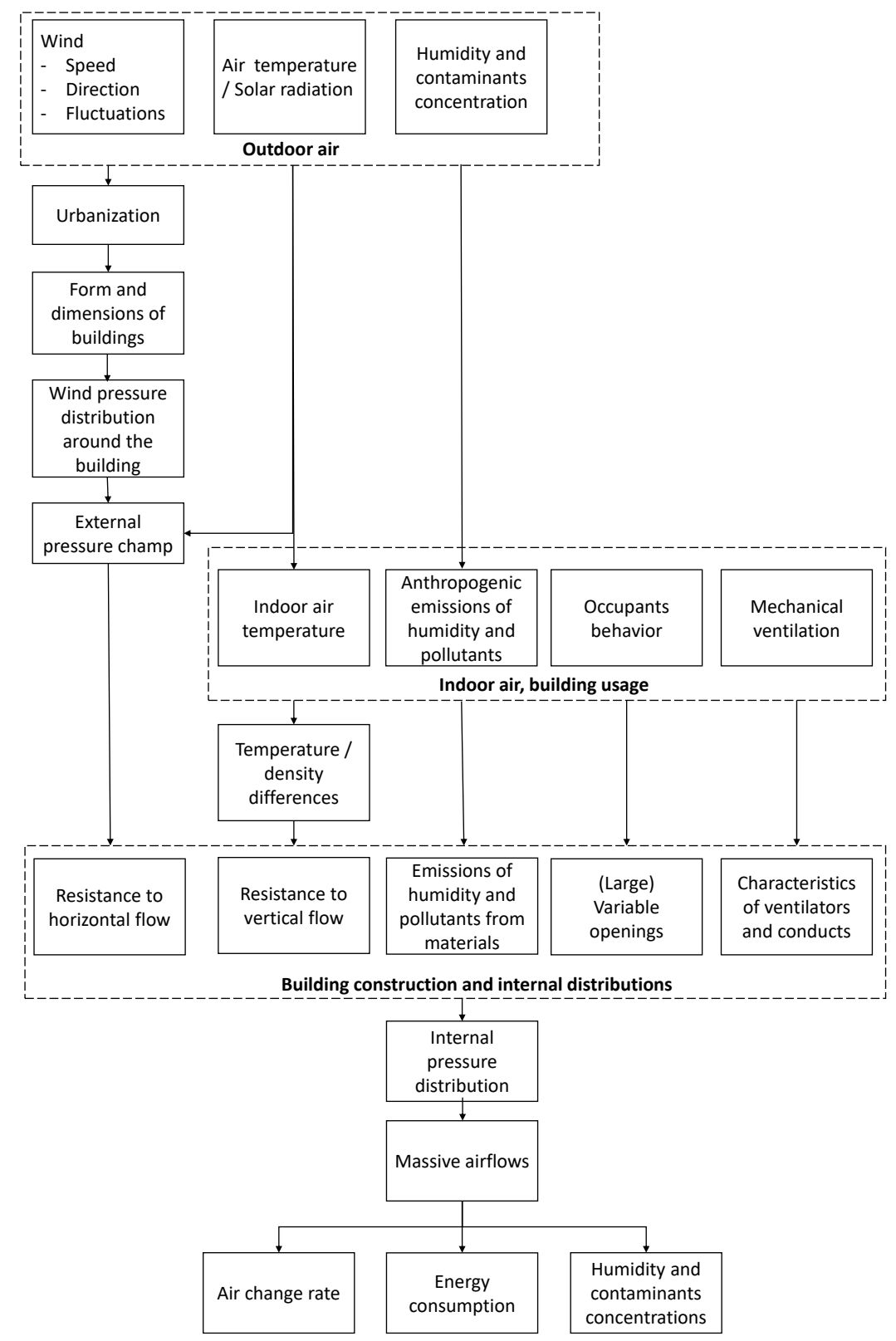

Figure 1 Influence factors and relations in the air movement domain inside and around the building [7]

forces, and the other one is often not taken into account in most natural ventilation studies. The influence of winds, in the sense of blocking, depends on the level of urbanization around buildings, the building form and dimensions, and orientation. As shown in Figure 1, these four factors mentioned before can be accounted for by a resistance to horizontal flow together with internal and external pressure distribution around the building. Similarly, the influence of the difference between indoor and outdoor temperatures can be accounted for by a resistance to vertical flow, which is dependant on the building height and opening sizes. The impact of all influencing factors related to the indoor air movements can be globally assessed in terms of three most parameters: $(i)$ the air change rate, (ii) energy consumption, and (iii) air quality.

\subsection{The role of natural ventilation}

In a building, the role of ventilation is crucial concerning two major points: the indoor air quality lcomfort and minimum air renewal rate) and energy consumption. In this regard, natural ventilation is wanted to efficiently provide a minimum air renewal rate to keep the air stale out from the room, and thus, avoiding the use of mechanical ventilation, leading to minimizing the energy 
consumption [8]. The latter depends on the outdoor ambient conditions. Promising results encountered higher energy savings around $17 \%-80 \%$, when having a fully automatic system, especially with a model predictive control algorithm [9]. In the case of tropical climate, a study showed no significant reduction when implementing night free cooling strategy (about $0.5 \%$ ); this was attributed to the small difference between the indoor and outdoor air temperatures [10].

\section{Thermal comfort}

The adequate implementation of natural ventilation in buildings strongly depends on the occupants' behavior, which is usually driven by their hygrothermal comfort needs. Many parameters influence these comfort needs, and can be classified into three categories: physical, physiological, and external; the indoor and outdoor conditions lair temperature, relative humidity, air currents), are among the physical parameters; the level of metabolic activity perform and the level of clothing, are some of the most important physiological parameters [11].

Several comfort indicators can be found in the literature. In summer, the standard ISO 7730 recommends the use of the following values for comfortable indoor conditions:

- A room temperature between 23 and $26^{\circ} \mathrm{C}$,

- The difference in vertical temperature must be less than $3^{\circ} \mathrm{C}$,

- An average indoor air speed less than $0.25 \mathrm{~m} \cdot \mathrm{s}^{-1}$,

- The degree of discomfort that measures thermal dissatisfaction.

Another parameter very evoked in the literature is the difference between the temperature of the indoor air and the mean radiant temperature of the surrounding walls. According to [12], a feeling of discomfort can appear beyond a temperature difference higher than $2^{\circ} \mathrm{C}$, between the indoor air temperature and that of the ceiling, and $3^{\circ} \mathrm{C}$ with that of the walls.

In regions with a significant temperature gradient between nighttime and daytime, night natural ventilation, if implemented adequately, arises as a good solution for the attenuation of the heat wave associated with the daytime period, leading to maintaining the thermal comfort for longer periods. Its application may be more attractive in office buildings, due to the absence of occupancy during nighttime. Its principle consists of cooling down the structure of the building when it is not occupied (nighttime), providing a heat sink that is available during the occupancy period (daytime). This heat sink absorbs the heat gains related to occupancy or equipment and maintains acceptable indoor conditions [11]. The cooling potential of nighttime ventilation can be assessed by the temperature difference between the indoor air and the surface of the wall (Figure 2).

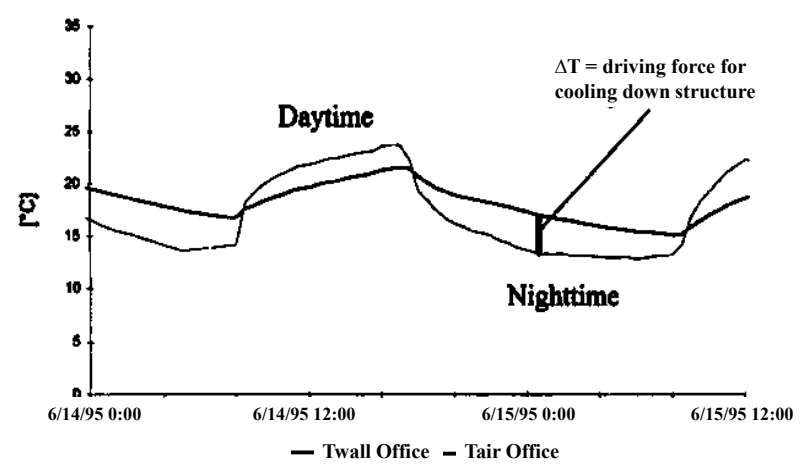

Figure 2 Cooling potential due to nighttime ventilation technique [11]

As observed in Figure 2, during nighttime, the temperature of the walls is higher than the air inside the office; therefore, heat transfer will occur outwardly (from the walls to the surrounding air), successfully cooling down the walls. In detail, the temperature difference between the indoor air and the wall surfaces is the consequence of the building interaction, among other parameters, such as the outdoor air and the sky temperature, the surface temperature of the surrounding buildings, and wind effects. Night natural ventilation strategies have been widely studied [9, 13-15].

However, different limitations are encountered depending on the site where the building is located; urban or suburban. Also, depending on the periods of occupancy in the building, implying that this strategy is useful for office buildings.

\section{Air infiltrations and leakages}

Air infiltrations and leakages are the unavoidable part of the natural ventilation process, due to imperfections in the envelope or joinery. They are important for indoor air quality, but if not controlled properly, they could become the leading cause of heating losses. Therefore, the quantification of the air-leakage rate represents an important issue for the prediction of the heat losses. Also, regarding the nature of the air leakages, their distribution around the envelope is often complicated to be determined $[16,17]$. 
Impact on energy consumption and performance of natural ventilation strategies

Although it is known that the use of natural ventilation systems might reduce the overall power consumption if we applied them correctly, how much will it reduce, depends on many parameters. When applicable, natural ventilation can compensate for cooling energy consumption and its energy costs and carbon dioxide emissions. The potential cooling energy that may be saved depends, of course, on the climate conditions of the building location and the internal and external heat gains $[18,19]$.

When having not quite favorable climate conditions for the implementation of natural ventilation, coupling it to a mechanic system remains possible, which is accomplished in Hybrid Natural Ventilation systems.

Among the performance indicators of natural ventilation strategies, a good indicator for evaluating the ventilation power is the level of air change per hour reached. Regarding energy consumption, a good indicator is the percentage of occupied hours where minimum mechanical ventilation rates are met [20].

One of the most critical limitations of natural ventilation usage lies in its understanding. Some of the advantages (1-5) and limitations (6-9) regarding its applicability are [21]:

1. Well accepted by occupants who understand it and control it very easily.

2. The investment required is very low or zero $[15,19]$.

3. The energy required for air transport is free.

4. It allows high flow rates, especially for passive cooling.

5. It does not crash or fail.

6. It does not work in noisy or polluted areas.

7. It does not work in places with a depth/height relation exceeds 2.5 (office landscape).

8. It hardly allows the heat recovery from exhaust air.

9. It provides a variable flow rate, which without proper controls, might not be necessary in relation to the needs.

\subsection{The concept of natural ventilation}

For a better understanding of the natural ventilation process, three essential aspects are introduced to define the concept of natural ventilation: How is it created? In which way can it be implemented in buildings? And, which architectural features can be employed? This can be illustrated in Figure 3. Natural ventilation is created by either buoyancy forces, wind forces, or a combination of both. These two forces can be exploited to ventilate a space by promoting the implementation of some strategies: single-sided ventilation, cross ventilation, or stack ventilation; and this, through some architectural features such as wind towers, wind scoops, chimneys, double facades, atria, among others [22]. Finally, the determination of the natural airflow rate depends on the strategies implemented.

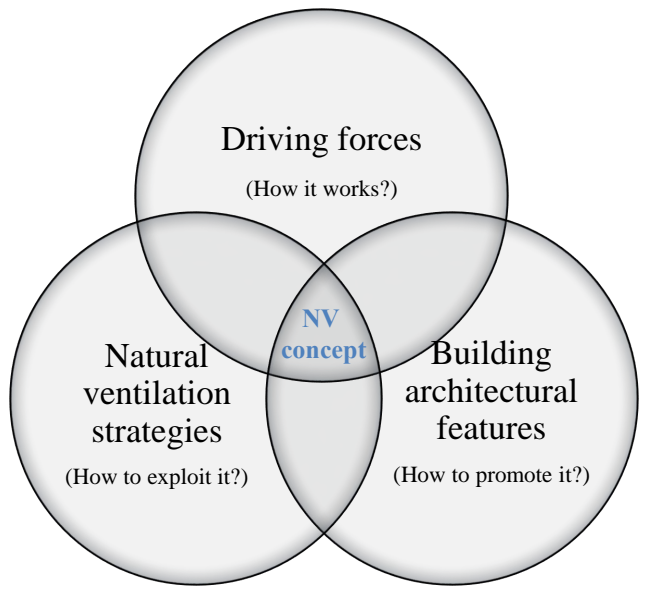

Figure 3 The natural ventilation concept

\section{Air flow due to wind forces}

In the case of wind-driven ventilation, to benefit the most from this natural force, it is recommended that the facade with openings of a building located in a windy place must be oriented perpendicularly to the wind direction, although not strictly necessary [23]. When the wind currents find in their path a building, a high-pressure zone is created over the windward side (or upside) of the building, and the leeward side (or downside) experiences an under-pressure zone (Figure 4 (a)). The other sides of the building (those in the wind direction) will also experience an under-pressure status (Figure 4 (b)) [22]. In general, the resulting dynamic pressure over the windward facade can be defined as a function of the wind speed using Bernoulli's principle, as presented in Equation (1):

$$
P_{v}=\frac{1}{2} \cdot \rho \cdot \mathcal{V}_{v}^{2} \quad[\mathrm{~Pa}]
$$

where $\rho$ represents the air density at outdoor temperature, and $\mathscr{V}_{v}$ is the wind speed at the opening height on the windward side. The resulting airflow rate inside the building due to wind effects depends on the windward-leeward pressure difference, as presented 
in Equation (2):

$$
\Delta P=\frac{1}{2} \cdot C_{p} \cdot \rho \cdot \mathscr{V}^{2} \quad[\mathrm{~Pa}]
$$

where $C_{p}$ is known as the pressure coefficient $[24,25]$.

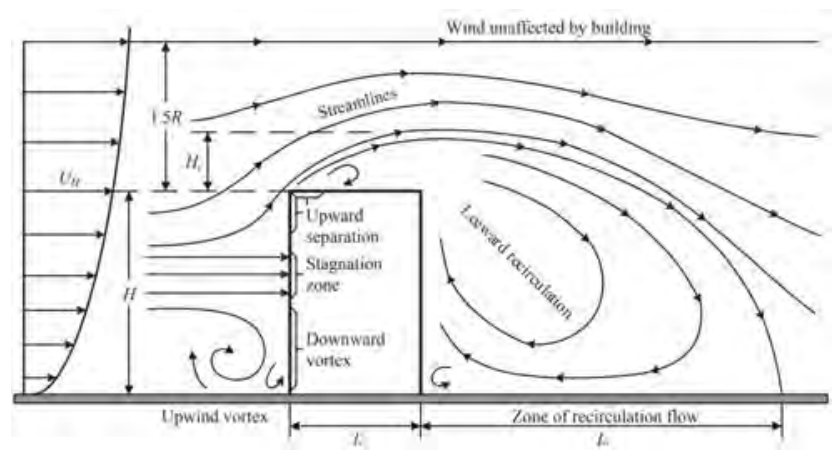

(a)

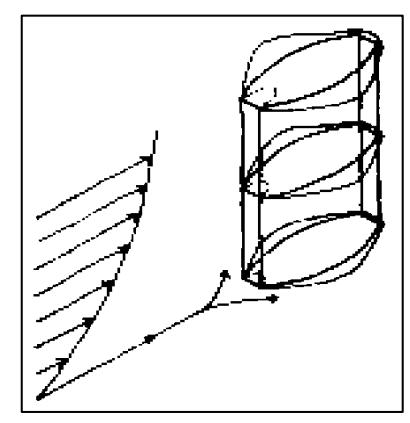

(b)

Figure 4 Representation of wind forces (a), and pressure distribution induced by wind (b) [22]

This pressure coefficient is introduced in the building domain to account for the pressure differences induced by the airflow over the building envelope. A simplified representation of these pressure differences is presented in Figure 4 (a), where the windward facade of the building experiences an overpressure, while the leeward facade experiences a pressure drop with respect to the static pressure of the freestream, named dynamic pressure $\left(P_{\infty}\right)$, defined by Equation (1). Thus, an Equation for $C_{p}$ can be written as presented in Equation (3) [24]:

$$
C_{p} \equiv \frac{P-P_{\infty}}{\frac{1}{2} \cdot \rho_{\infty} \cdot \mathcal{V}_{\infty}^{2}} \quad[-]
$$

where $P$ is the value of the pressure where the coefficient is being evaluated. $\rho_{\infty}$ and $\mathcal{V}_{\infty}$ represent the density and velocity of the airflow on the freestream region, respectively. The windward facade will present positive values of $C_{p}$, while the leeward facade, negative values. An overview of acceptable models to predict $C_{p}$ values in buildings are presented in $\S 3.3$.

\section{Air flow due to buoyancy forces}

A density gradient can induce air movement between two regions (buoyancy forces). This gradient can be created by either different gas concentrations, a temperature difference, a humidity difference, or a combination of these three. In buildings, this mentioned before can cause air movement within the same zone, between different zones within the building, between two facades [21], and between the inside and outside of the building (Figure 5). The reason lies in that this density gradient creates a pressure difference between the zones, generally referred to as static pressure. In this case, the overall pressure difference can be defined as a function of the air density of two zones (indoor and outdoor air), by Bernoulli's principle as presented in Equation (4):

$$
\Delta P=\Delta \rho \cdot g \cdot \mathscr{Z}=\left[\rho_{o a}-\rho_{i a}\right] \cdot g \cdot \mathscr{Z}
$$

where $g$ is the gravitational acceleration, and $\mathscr{Z}$ is the height between an upper and a lower opening (Figure 5 (a)). Note that this Equation is under the assumption that the air entering the building is at outdoor air density $\left(\rho_{o a}\right)$, and the air leaving the building is at indoor air density $\left(\rho_{i a}\right)$. Also, in Equation (4), it is considered that the height of the openings is negligible with respect to their separation ( $\mathscr{E}$ ).

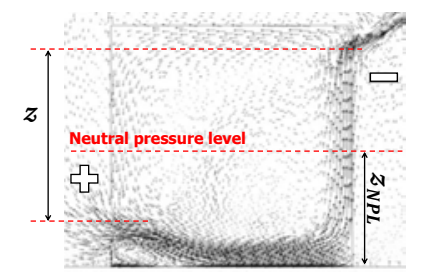

(a)

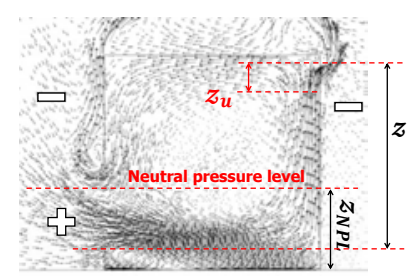

(b)
Figure 5 Air movement due to buoyancy forces: (a) small openings, (b) one large lower opening [26]

However, when the height of the openings is not negligible (case of large openings), the use of Equation (4) might lead to either an underestimation or an overestimation of this overall pressure difference. In this case, the overall pressure difference can be defined as in Equation (5), for the outgoing airflow $[26,27]$ :

$$
\Delta P=\int_{Z-\mathscr{E}_{N P L}-z_{U}}^{Z-\mathscr{E}_{N P L}} \Delta \rho \cdot g \cdot d z \quad[\mathrm{~Pa}]
$$

where $Z$ represents the vertical distance from the lower edge of the lower opening $(L)$ to the upper edge of the upper opening $(U)$; with height $z_{U}$ (Figure 5 (b)). The vertical distance $\mathscr{Z}_{N P L}$ represents the height of the neutral pressure level (NPL), where the indoor-outdoor pressure difference is equal to zero, with respect to the floor. Different ways to determine this height have been 
reported in the literature $[21,26,28]$. For instance, the value of $\mathscr{Z}_{N P L}$ can be determined by Equation (6) [26]:

$$
\mathscr{Z}_{N P L}=\frac{\gamma^{2}}{1+\gamma^{2}} \cdot \mathscr{Z} \quad[\mathrm{m}]
$$

where $\gamma$ is the opening ratio, as presented in Equation (7):

$$
\gamma=\frac{C_{d_{U}} \cdot S_{U}}{C_{d_{L}} \cdot S_{L}} \quad[-]
$$

where $C_{d}$ and $S$ represent the discharge coefficient and the effective opening area, respectively. This vertical distance depends on the position and height of the openings. For an enclosure with a single opening, the NPL will be established at half the height of this opening. For the same enclosure with another opening over the previous one on the same side, the NPL will be established at half the distance between these openings if they are of the same size. However, if they differ in size, the NPL will tend to get closer to the larger openings; and the height of the NPL is proportional to the square of the opening surface [21].

\section{Air flow due to a combined effect}

If placing the openings at the correct location, wind effects will join the thermal buoyancy effect, reinforcing the ventilation airflow rate. On the contrary, not placing them correctly or if the building is not correctly oriented, the wind will mitigate the thermal buoyancy effect reducing the building ventilation. This can be observed in Figure 6 (a), where the openings are correctly located, improving the airflow traversing the building. However, in (b), the openings are not correctly located, causing zero airflow (neutralizing both effects) at a specific wind speed value [21].

In this interaction, the wind turbulence effect is more important than in cross-ventilation configuration [29]. However, significant differences can be observed concerning the complexity of this interaction regarding theoretical or experimental approaches [30].

\section{Estimation of the natural ventilation airflow rate}

Depending on the natural ventilation strategy implemented, the natural airflow rate can be assessed using different methods. Such methods can be grouped into two categories: Modeling and experimental techniques. For the determination of the airflow rate, all modeling techniques require the knowledge of the airflow capacity of the openings employed. Thus, hereafter, we
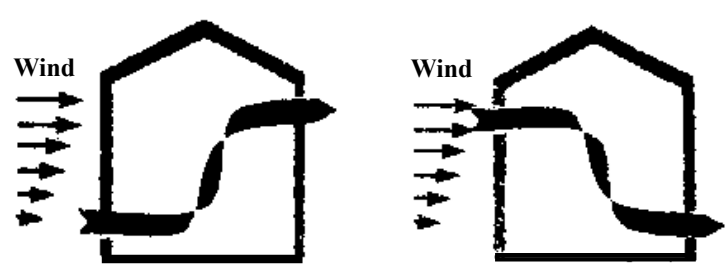

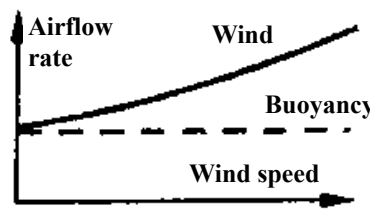

(a)

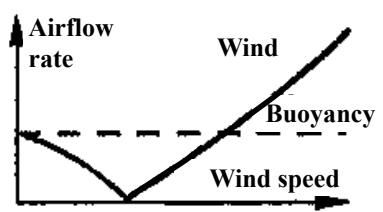

(b)
Figure 6 Stack ventilation with: (a) assisting winds, and (b) opposing winds [22]

address this before in the following section.

\subsection{Airflow capacity of an opening}

\section{Theoretical airflow-pressure relation}

A theoretical Equation describing the airflow rate caused by a pressure difference between the upstream and downstream of an opening, can be written using Bernoulli's equation as in Equation (8):

$$
\dot{V}=S \cdot \sqrt{\frac{2 \cdot \Delta P}{\rho}} \quad\left[\mathrm{m}^{3} \cdot \mathrm{s}^{-1}\right]
$$

where $\dot{V}$ represents the airflow rate in $\mathrm{m}^{3} \cdot \mathrm{s}^{-1}$ and $S$ represents the area of free gap sections of the opening $\mathrm{m}^{2}$ (usually called effective area $S_{\text {eff }}$ ). This Equation considers a non-frictional fully developed turbulent fluid flow through the opening. If needed, the friction characteristics of the opening can be grouped in a single coefficient named the discharge coefficient $\left[C_{d}\right]$ which multiples Equation (8) here before.

\section{Empirical airflow-pressure relation}

Moreover, for any fluid flow through an opening, an empirical Equation representing the airflow rate caused by a pressure difference between the upstream and downstream of an opening has been shown to follow Equation (9):

$$
\dot{V}=\mathscr{C} \cdot[\Delta P]^{n} \quad\left[\mathrm{~m}^{3} \cdot \mathrm{s}^{-1}\right]
$$

where $\mathscr{C}$ is called the airflow rate coefficient in $\mathrm{m}^{3} \cdot \mathrm{s}^{-1} \cdot \mathrm{Pa}^{-n}$. 
Its value depends on the effective area of the opening, and also considers its friction characteristics. The exponent $n$ is called the flow exponent: it takes the value of 0.5 for a fully developed turbulent flow and 1 for a laminar flow [31]; for values in between, the flow is said to be partially developed. It has been shown that Equation (9) describes the best, the air-leakages rate of a room or a building, where it can be small and big holes due to imperfections [32].

Daler et al. in 1982, as found in [33], reported the airflow capacity of bottom and side hung openings, for different opening degrees and as a function of a room indoor-outdoor temperature difference (Figures 7-8). One of these types of openings, the bottom-hung window (also known as tilted window), is the same as the ones implemented in our test building.

\section{Discharge coefficient and effective area of an opening}

This coefficient can be defined as the ratio of the empirical (or real) airflow rate to the theoretical (or ideal) airflow rate, translating the fact that the free gap area lor jet section) is smaller than the total area of the opening [34]. Various experimental studies have been interested in the dependence the discharge coefficient presents when the pressure around the opening varies. Flourentzou et al. in 1998 [27] performed tracer gas and velocity measurements in situ in a three-level stack ventilated building to determine the $C_{d}$. A value of $0.6 \pm 0.1$ was found, and thus, it was stated that: the accepted value for the discharge coefficient was confirmed once again (Figure 9).

Heiselberg et al. in 2001 [35], performed airflow rate and pressure measurements at the opening in a laboratory set-up, and determined $C_{d}$ values for openings similar to ours, using Equation (8) (Figure 10). It was concluded that the use of a constant value could lead to serious errors in the prediction of airflow capacity, because their experimental results showed that the discharge coefficient changed with the effective area and the type of opening, as well as, with the temperature difference. Also, for the three types of opening they tested, the value of the discharge coefficient slightly decreases as the pressure difference increases.

Costola and Etheridge in 2008 [36], performed pressure measurements in a scaled model in wind tunnel experiments, consisting of a stack and wind-assisted strategies. The scaled model included one small orifice at ground level and one stack opening at the top. They reported $C_{d}$ values (named $C_{z}$ ) for both the orifice and the stack opening, where the values of $C_{d}$ for the former resulted in around 0.7 for either still air, or wind-assisted $10^{\circ}$ and $180^{\circ}$ ) strategies; similar to those in Figures 10 and 7. However, for the stack opening, $C_{d}$ values changed considerably depending on the Reynolds number, as shown in Figures 11 and 12, for still air and wind-assisted strategies, respectively. In the case of the still air strategy, the average $C_{d}$ value was used, and in the case of the wind-assisted strategy, an average value from the constant region (from a $R e$ of about 600 ) was taken.

Moreover, [37] performed an experimental study with a wind tunnel using a scaled room model with several bottom-hung windows and Computational Fluid Dynamics (CFD) simulations. By determining the friction factor $\xi_{v}$ of the opening $\left(S_{\text {eff }}=0.377 \mathrm{~m}^{2}\right)$ to be equal to 28.9, a $C_{d}$ value of 0.67 was determined using Equation (10):

$$
C_{d}=\frac{1}{\sqrt{1+\xi_{v} \cdot\left(\frac{S_{e f f}}{S_{f o}}\right)^{2}}} \quad[-]
$$

where $S_{f o}$ stands for the area of the entire section of the opening $\left(1.82 \mathrm{~m}^{2}\right)$. $S_{\text {eff }}$ represents the effective area of the opening. Van Paassen et al. in 1998 [38] proposed Equation (11) to define the effective area $S_{\text {eff }}$ as a function of the opening angle, for tilted windows (bottom hung or side hung):

$$
S_{e f f}=\sqrt{\frac{1}{\frac{1}{(z \cdot w)^{2}}+\frac{1}{\left[2 \cdot z \cdot w \cdot \sin \left(\frac{\phi}{2}\right)+z^{2} \cdot \sin \phi\right]^{2}}}} \quad\left[\mathrm{~m}^{2}\right]
$$

where $z$ and $w$ represent the height and width of the opening, respectively, and $\phi$ represents the opening-angle $\left(0-90^{\circ}\right)$. The same Equation was used latter by [39] for bottom hung openings. Other ways to calculate this area can be encountered in $[37,40]$.

Other models have been reported for the estimation of the discharge coefficient. The authors in [41], proposed an empirical model for $C_{d}$ as a function of the ratio between the heights of the opening $(z)$ and the room $(\mathscr{Z})$, as presented in Equation (12):

$$
C_{d}=0.609 \cdot \frac{z}{\mathscr{L}}-0.066 \quad \text { if } \quad 0.2 \leq \frac{z}{\mathscr{L}} \leq 0.9
$$

On the contrary, in [42], another empirical model for $C_{d}$ is proposed as a function of the indoor-outdoor temperature difference, accounting for thermal buoyancy effects, as presented in Equation (13):

$$
\begin{gathered}
C_{d}=0.4+0.0045 \cdot\left|T_{i a}-T_{o a}\right| \quad \text { for } \\
0.5 \leq\left|T_{i a}-T_{o a}\right| \leq 40 .
\end{gathered}
$$

Moreover, a comparison of implementing these models, showing their impact on the natural airflow rate, can be found in [43], concluding that the estimation of this 


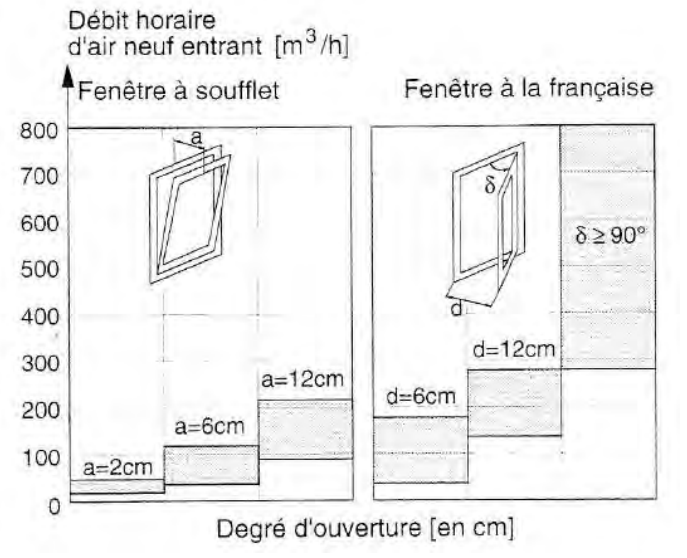

Figure 7 Airflow capacity of bottom and side hung windows depending on the opening degree [33]

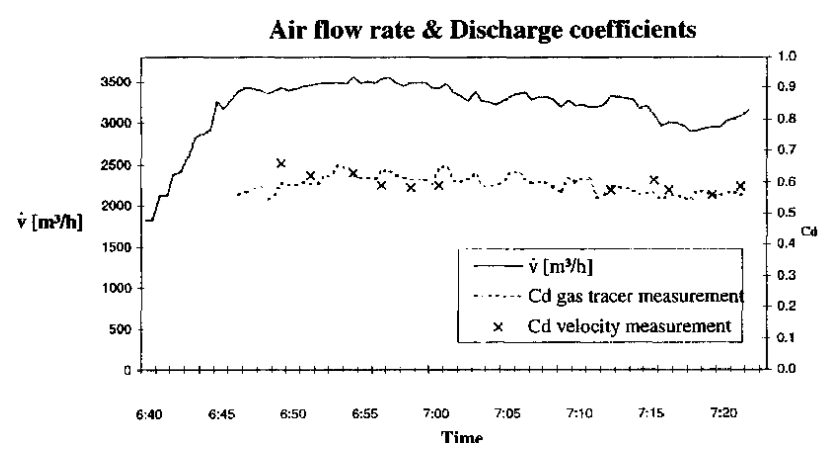

Figure 9 Values of discharge coefficient obtained by [27]

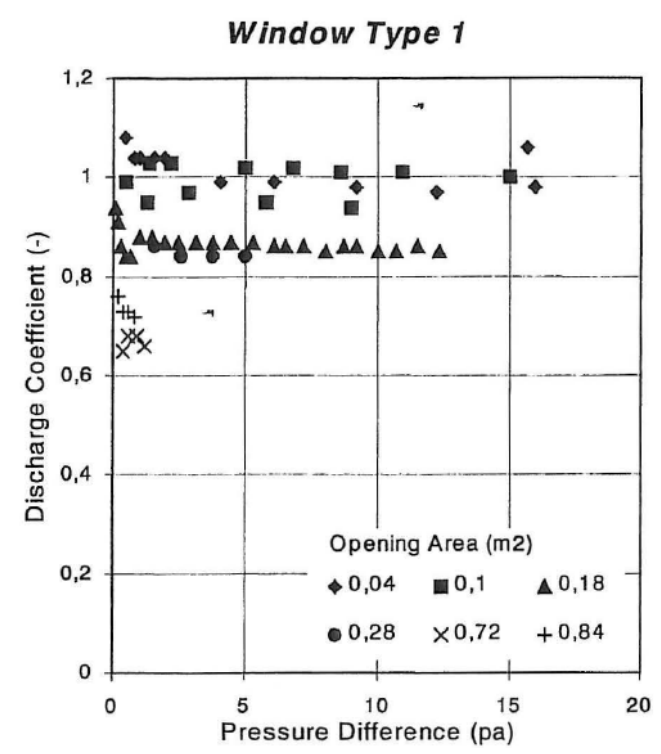

Figure 10 Values of discharge coefficient obtained by [35]

coefficient should be performed attentively. Nevertheless, to determine either the airflow capacity or the discharge

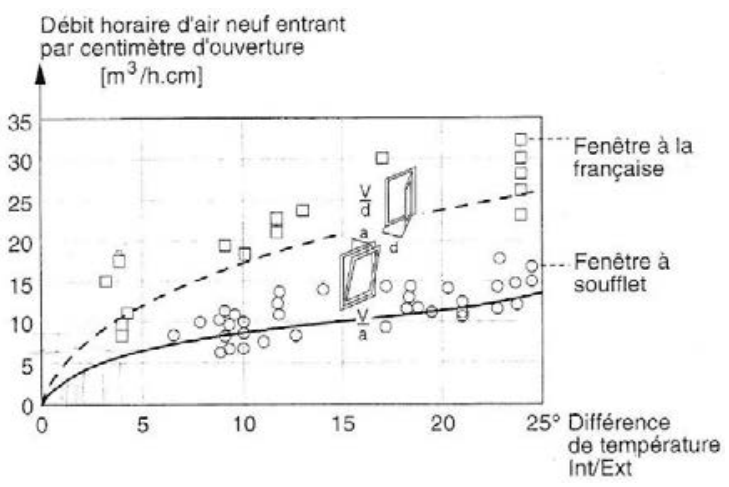

Figure 8 Variation of the airflow capacity of bottom and side hung windows as a function the indoor-outdoor temperature [33]

coefficient of an opening, experimental data is needed. Thus, hereafter the experimental and modeling techniques employed to determine such characteristics of the openings.

\subsection{Experimental techniques and methods}

Many experimental techniques have been developed/employed to determine the airflow rate in naturally ventilated buildings for the case of openings closed or opened. In this section, it is intended to present information about reported airflow rate levels attained for a given wind speed and direction, temperature difference, and the experimental technique employed. Nevertheless, we include the size and type of building and openings. A summary and comparison of these techniques are presented in Table 1.

The majority of the studies in the literature employed these techniques for cases with simple configurations, where the airflow path is well known (single-sided, cross, or stack ventilation). Thus, for cases where a building has a quite number of openings, the assumption of a specific airflow path is rendered moot.

\section{Airtightness tests}

Kronvall and Persily developed the K-P model, as found in [31], to estimate the annual natural air-leakage rate of a building using airtightness tests as in Equation (14):

$$
\overline{a c h}_{\text {natural }} \equiv \frac{\operatorname{ach}_{50}}{20} \quad\left[\mathrm{~h}^{-1}\right]
$$

which later employed data from tests performed in more than 40 houses, and achieved the linear regression as in 


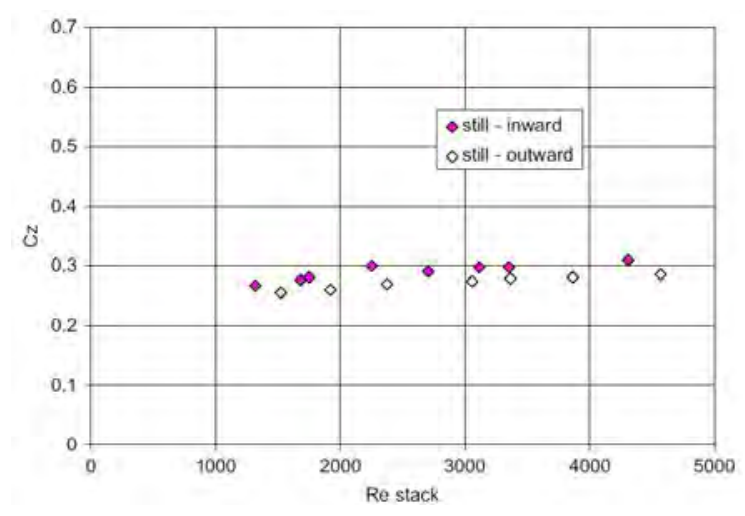

Figure 11 Values of stack discharge coefficients for inward and outward flow in still air [36]

Equation (15):

$$
\overline{a c h}_{\text {natural }} \approx \frac{a c h_{50}}{18}-0.08 \quad\left[\mathrm{~h}^{-1}\right]
$$

where $a c h_{50}$ referred to the value of $a c h$ at a pressure difference of 50 Pa measured via blower door tests.

Later on, this method was employed again to determine the air-leakage rate [44], performed nine in situ airtightness tests (or blower door tests) to estimate the air change rate at natural pressure levels of a full-scale building of volume. The air infiltration rate, for either windows closed and opened, was determined using the K-P model in Equation (14) (Figure 13).

Moreover, several in situ airtightness tests in the same passive building were performed, to determine the airflow characteristics of each opening [45-47]. As stated, such airtightness tests must be performed on no windy days, preferably. For the airflow characteristics, the following steps are proposed: (i) With openings closed, perform a number of airtightness tests to determine the infiltration airflow rate (air leakages); ( $\mathrm{ii}$ ) with openings opened lone by one or all at once for total building air change potential), repeat the tests (more than one blower door might be needed); ( iii) using both equations (8) and (9), an Equation similar to Equation (9) can be drawn, where the value of $\mathscr{C}$ is determined from the first two steps. In this way, the airflow characteristics of all openings were estimated (Figure 14) and compared results with [44].

\section{Direct air velocity, pressure and volume airflow measurements}

This technique often requires several sensors due to a unique point of measurement possible at a time. Also, because of weak airspeed values resulted when indoor air is driven by thermal buoyancy, the sensors may require to

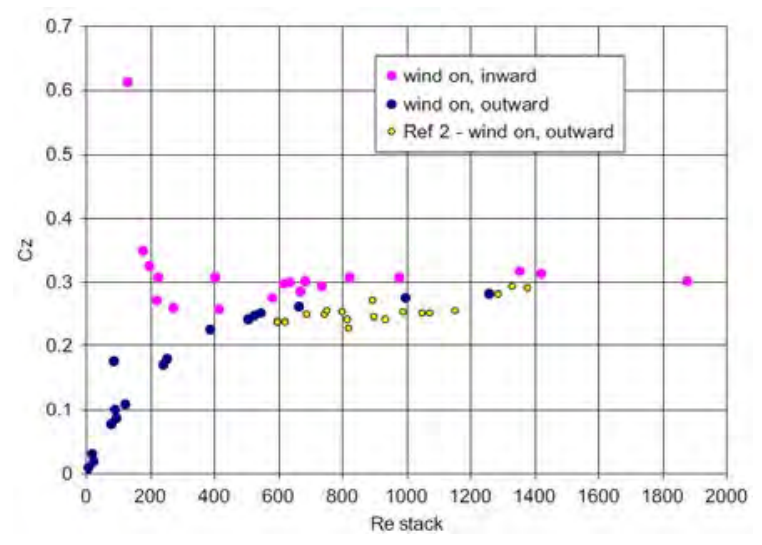

Figure 12 Values of stack discharge coefficients for inward and outward flow with wind [36]

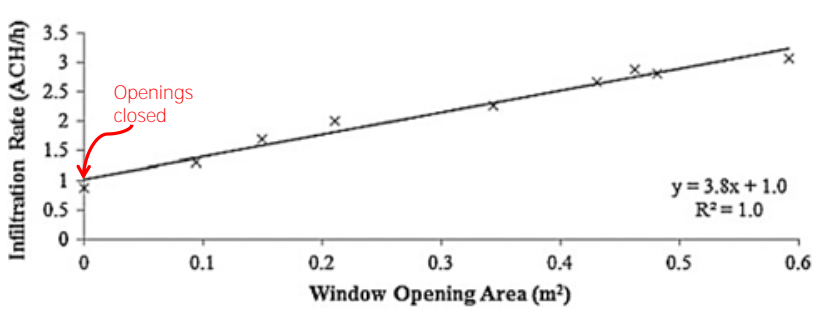

Figure 13 Results of the blower door tests with window opening, adapted from [44]

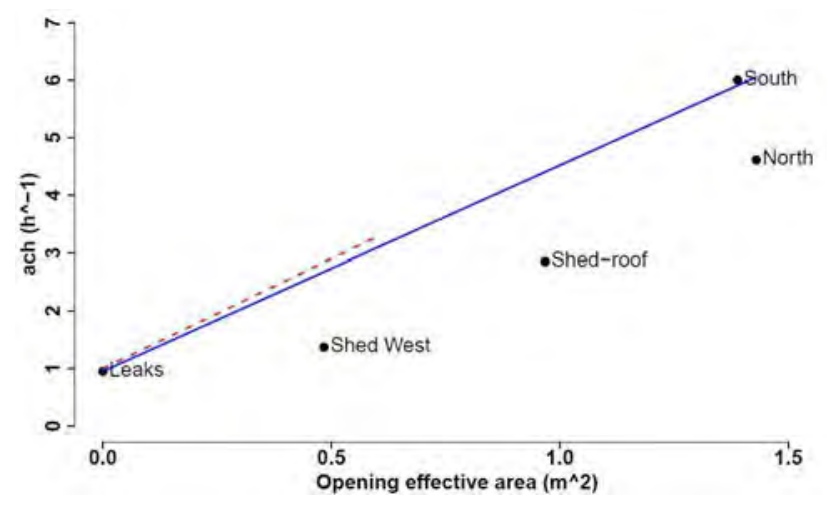

Figure 14 Results of ach as a function of the opening effective-area: red dashed line [44], and black dots [47]

be highly sensitive. Such highly sensitive sensors could strongly increase the budget needed to perform proper experimental studies. It should be noted that the smaller the effective opening area, the greater the perturbation the sensors may be introduced. However, after performing the measurements, a model is needed to translate the airspeed values to airflow values, which often requires certain characteristics not met regarding openings sizing and distribution. Nevertheless, various experimental studies can be found in the literature regarding such type of measurements [29, 37, 47-53]. 
The effect of wind on the performance of the stack ventilation was studied by performing airspeed measurements in a full-scale building [29], proving that wind effects have a considerable influence that could change up to $350 \%$. They reported air change rate values, for stack and wind only, and also reported the variation of the air change rate, with respect to the wind speed. The wind effects were also studied to estimate the natural ventilation airflow resulted from a cross-ventilation strategy in a full-scale building with a sizeable windward window and a small leeward window [49]. A conventional anemometer cup anemometer was installed at the windward window, and several omni-anemometers were installed at the leeward window. This leeward window was discretized, and the airflow was determined after a rather rigorous statistical model based on Artificial Neural Networks.

These types of omni-anemometers were also employed in another full-scale building study, where the indoor air movement was reported to be mostly driven by thermal buoyancy $[47,51]$. Airspeed values between 0.01 and 0.25 $\mathrm{m} \cdot \mathrm{s}^{-1}$ were reported near the floor and a height of $1.70 \mathrm{~m}$ from the floor.

\section{Wind tunnel for scaled models}

For natural ventilation, the implementation of the wind tunnel technique normally requires the development of reduced-scale building models that fit the test cavity. Most studies only implement such a technique for testing wind effects in individual scaled buildings [37, 54-58]. However, this technique can be used to study the wind effects on building clusters [59].

The authors in [55] (in an enclosure of $748 \mathrm{~m}^{3}$ ) and, in [54] (in an enclosure of $93 \mathrm{~m}^{3}$ ), compared measured data from wind tunnel experiments with different existing models, aiming to evaluate and improve the existing models for the case of single-sided ventilation (Figures 15-16).

\section{Tracer gas decay method}

The airflow rate or the air change rate per hour can be determined directly using this technique $[27,49,52,60]$. As a standardized costume, the "gas" chosen in this technique is often different from the common components of normal air (i.e., Argon, $\mathrm{SF}_{6}$ ), in this way, the components in the air may not interfere with the instrument implemented to measure the number of particles of such gas per unit time. Depending on the tracer gas chosen, the experimental protocol can be found in literature, where the accuracy of the method strongly depends on assuring a well-mixed of the tracer gas inside the building room. However, considering the natural ppm levels of ambient $\mathrm{CO}_{2}$, it

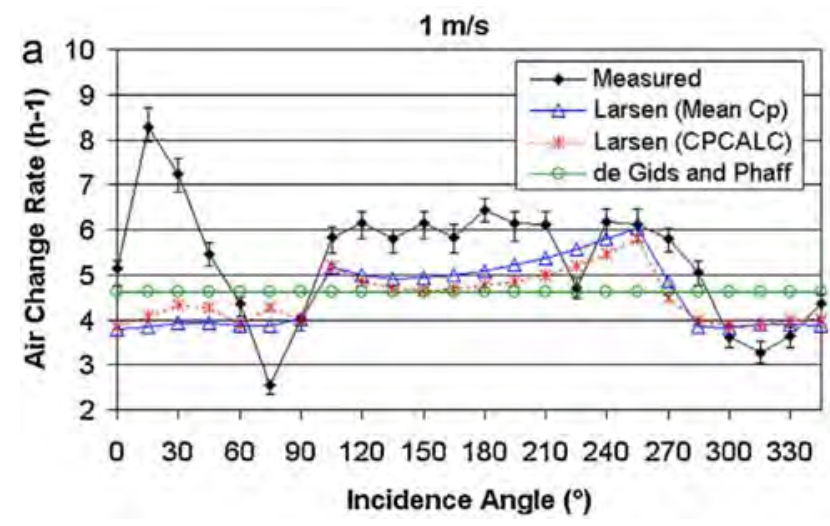

Figure 15 Comparisons between the experimental and simulation results performed into the PowerDomus software for the wind tunnel case [55]

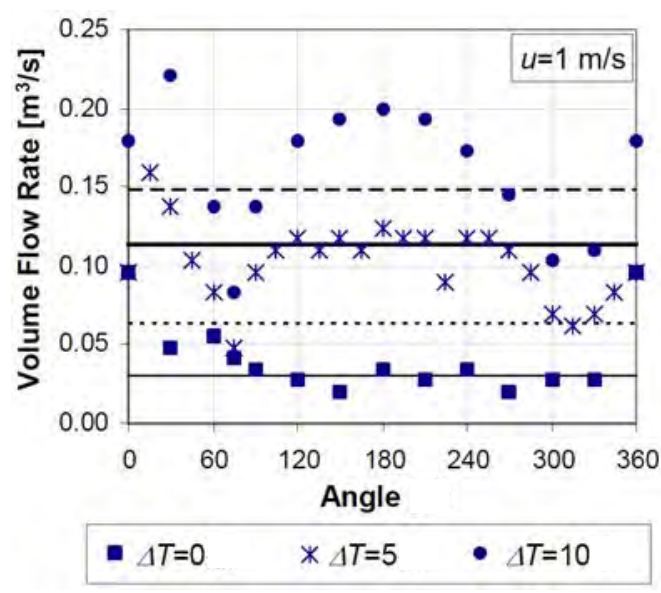

Figure 16 Measured and calculated volume flow rates: Warren \& Parkins (black thin line), De Gids \& Phaff (black dotted line, $\Delta T=0{ }^{\circ} \mathrm{C}$ ), and De Gids \& Phaff (black thick line, $\Delta T=5^{\circ} \mathrm{C}$ )

might be a suitable and cheaper choice than other tracer gases.

In fact, a study implementing this technique couple with others in a downscaled building, performed 15 infiltration tests reaching a $\mathrm{CO}_{2}$ level between 3000 to $10000 \mathrm{ppm}$ [52]. The accuracy of such a method in the estimation of the airflow rate can reach acceptable values $[60,61]$. An accuracy of $20 \%$ when comparing an airflow estimated from airspeed measurements [27].

\section{Scaled models and dimensional analysis}

The combination of wind and buoyancy effects was studied in a small-scaled building-like, through the implementation of dimensionless numbers, where the use of a saline fluid to represent the air fluid resulted from the similitude principle from dimensional analysis [62]. 
Table 1 Experimental techniques to estimate the airflow rate due to natural ventilation at building scale

\begin{tabular}{|c|c|c|c|}
\hline Technique & $\begin{array}{l}\text { Technical requirements } \\
\text { and features }\end{array}$ & $\begin{array}{l}\text { Difficulties in } \\
\text { implementation }\end{array}$ & Type of study \\
\hline $\begin{array}{l}\text { Airtightness tests (or } \\
\text { Blower door tests] } \\
\text { [44-47] }\end{array}$ & $\begin{array}{l}\text { Full-scale buildings. } \\
\text { No extra modeling needed.* } \\
\text { Can determine air-leakages } \\
\text { and opening capacity. } \\
\text { Do not account for wind- nor } \\
\Delta \text { T- driven situations. } \\
\text { Building submitted to } \\
\text { unrealistic pressure levels. }\end{array}$ & $\begin{array}{l}\text { More than one blower door, } \\
\text { depending on the building. } \\
\text { High budget. } \\
\text { Airstreams blocking effects } \\
\text { due to indoor furniture } \\
\text { and partitions. }\end{array}$ & in situ \\
\hline $\begin{array}{l}\text { Direct air velocity and } \\
\text { pressure measurements } \\
{[29,37,47-50]} \\
{[51-53]}\end{array}$ & $\begin{array}{l}\text { Extra modeling needed.* } \\
\text { Can account for wind- and } \\
\Delta T \text { - driven situations. }\end{array}$ & $\begin{array}{l}\text { Several sensors, depending } \\
\text { on the distribution of the } \\
\text { openings. } \\
\text { High budget. } \\
\text { Careful placement, } \\
\text { depending on sensor type. } \\
\text { Mild-to-High interference } \\
\text { with local airstreams. }\end{array}$ & $\begin{array}{l}\text { Laboratory } \\
\text { and in situ }\end{array}$ \\
\hline $\begin{array}{l}\text { Tracer gas method } \\
{[27,49,52,60,61,63]}\end{array}$ & $\begin{array}{l}\text { No air-related gases needed. } \\
\text { No extra modeling needed.* } \\
\text { To determine air-leakages } \\
\text { only. } \\
\text { Can account for wind- and } \\
\Delta \mathrm{T} \text { - driven situations. }\end{array}$ & $\begin{array}{l}\text { Building-materials with } \\
\text { small porosity. } \\
\text { High budget. } \\
\text { Keeping a well-mixed } \\
\text { environment through the } \\
\text { decaying process. }\end{array}$ & in situ \\
\hline $\begin{array}{l}\text { Particle image velocimetry } \\
{[35,40]}\end{array}$ & $\begin{array}{l}\text { Extra modeling needed. } \\
\text { Can account for wind- and } \\
\Delta \mathrm{T} \text { - driven situations. }\end{array}$ & High budget. & $\begin{array}{l}\text { Laboratory } \\
\text { and in situ }\end{array}$ \\
\hline $\begin{array}{l}\text { Wind tunnel for scaled } \\
\text { models } \\
{[37,54,55,55,57,59]}\end{array}$ & $\begin{array}{l}\text { Extra modeling needed.* } \\
\text { Scaled-building designs. } \\
\text { Can only account for wind- } \\
\text { driven situations. }\end{array}$ & $\begin{array}{l}\text { High budget. } \\
\text { Extra tests to determine } \\
\text { pressure correction factors } \\
\text { due to building blocking. }\end{array}$ & Laboratory \\
\hline $\begin{array}{l}\text { Scaled models and } \\
\text { dimensional analysis } \\
\text { [62] }\end{array}$ & Extra modeling needed.* & $\begin{array}{l}\text { No standard methods are } \\
\text { mandatory for an } \\
\text { experimental bench. }\end{array}$ & Laboratory \\
\hline
\end{tabular}

\subsection{Modeling techniques}

The local estimation of the impact of wind effects on the natural airflow rate remains complicated in buildings with non-standard architectural features. These devices, forming part of the building envelope and being either openings or entire facades with a non-standard morphology, make it difficult to accurately take into account the effects of the wind on the instantaneous airflow rate. The reason lies in the need to know the values of the external pressure coefficients and the discharge coefficients of its opening, which are not always found in the literature for their consideration in the use of numerical airflow simulation tools.

\section{Empirical correlations}

Many investigations have been undertaken for the estimation of this coefficient $[25,55,64-66]$. The authors in [64], presented Equation (16) empirical model for the determination of this coefficient as a function of the wind direction $(\phi)$ :

$$
\begin{gathered}
C_{p}=0.75-1.05 \cdot \frac{\phi}{90} \quad \text { if } \quad \phi \leq 90^{\circ} \\
C_{p}=-0.45+1.05 \cdot \frac{\phi}{90} \quad \text { if } \quad \phi \geq 90^{\circ} .
\end{gathered}
$$

On the other hand, the authors in [65] and [66], proposed guidelines to determine the model for this coefficient depending on various geometrical parameters of the building and the wind incident angle. Swami and Chandra 
[65] reported in Equation (17):

$$
\begin{aligned}
C_{p}= & C_{p}(\phi=0) \cdot \ln \left[1.248-0.703 \cdot \sin \frac{\phi}{2}\right. \\
& -1.175 \cdot \sin ^{2} \frac{\phi}{2}+0.131 \cdot \sin ^{3}(2 \cdot \phi \cdot G) \\
& +0.769 \cdot \cos \frac{\phi}{2}+0.07 \cdot G^{2} \cdot \sin ^{2} \frac{\phi}{2} \\
& +0.717 \cdot \cos ^{2} \frac{\phi}{2}
\end{aligned}
$$

where $\phi$ goes from 0 to $180^{\circ}$; for higher angles are obtained by symmetry. $G$ corresponds to the natural logarithm of the side ratio (ratio of the lengths of adjacent walls). For vertical walls, [65] recommend using a value of 0.6 for the pressure coefficient at zero incidence angle [55].

The authors [67], in their proposition for developing a new integrated design tool for naturally ventilated buildings, the wind effect on the proposed ventilation model took into consideration a fitted regression model for predicting $C_{p}$ values for each angle (Figure 17).

This regression model was fitted over $C_{p}$ values computed using experimental data from pressure measurements and the Equation for this coefficient presented in §2.2. This regression model is similar to Equation (17), but without considering logarithms, the parameter $G$, and the whole angle was considered.

Moreover, [68] developed an empirical model for the estimation of $C_{p}$ as a function of the wind incident angle by fitting regression models, as shown in Figure 18.

Nevertheless, all these models are applicable to buildings with simple rectangular geometries. For cases where other geometries should be taken into account, the standard EN 1991-1-4:2005 (Euro code 1) presents guidelines for the estimation of $C_{p}$ values.

\section{Analytical and numerical approaches}

Different analytical models have been developed and proposed for the determination of the natural airflow rate in terms of the driving forces, depending on the natural ventilation strategy implemented.

In [69] and later in [70], reported a review of natural ventilation models for simple opening configurations, and classified them in two groups: analytical and empirical models, and network models. The analytical models are developed by applying the conservation equations to a specific configuration. According to the network modeling concept, a building is represented by a grid composed of several pressure nodes and flow paths (Figure 19)
[32]. These pressure nodes could represent the pressure of a single zone inside the building or the pressure of the exterior environment (Figure 19 black ovals). The flow paths represent each opening in the building, e.g., windows, doors, etc. (Figure 19 squares).

Bernoulli's equation is then applied to relate every pressure node (taking into account a reference level). For instance, in the case of zone 1 (pressure node 1) assuming that the reference level is at the height of the flow path between nodes 1 and $2^{\prime}$, and the pressure is constant on the zone of each node, Bernoulli's general equation yield (Equation (18)):

$$
P_{2^{\prime}}+\frac{1}{2} \cdot \rho_{2^{\prime}} \cdot \mathcal{V}_{2^{\prime}}^{2}=P_{1} \quad[\mathrm{~Pa}]
$$

and in the case where the flow path between nodes 1 and 2 is located at a height of $\mathscr{L}_{2}$ with respect to the flow path between nodes 1 and $2^{\prime}$, then (Equation (19)):

$$
P_{1}+g \cdot \rho_{2} \cdot \mathscr{Z}_{2}=P_{2}+\frac{1}{2} \cdot \rho_{2} \cdot \mathscr{V}_{2}^{2} \quad[\mathrm{~Pa}]
$$

both Equations yield (Equation (20)):

$$
P_{2^{\prime}}+\frac{1}{2} \cdot \rho_{2^{\prime}} \cdot \mathcal{V}_{2^{\prime}}^{2}+g \cdot \rho_{2} \cdot \mathscr{Z}_{2}=P_{2}+\frac{1}{2} \cdot \rho_{2} \cdot \mathscr{V}_{2}^{2} \quad[\mathrm{~Pa}] \cdot \text { (20) }
$$

Finally, all flow paths of one zone are related by writing the flow conservation equation. For instance, if a steady state is considered, for pressure node 1 results in Equation (21):

$$
\dot{m}_{12^{\prime}}=\dot{m}_{12} \quad\left[\mathrm{~kg} \cdot \mathrm{s}^{-1}\right] .
$$

The previous equation can be expressed in terms of pressure by using the Equation relating the flow rate through an opening at the power of $\mathrm{n}$. The most common numerical method to solve the system of equations is Newton-Raphson's method. Various software implementing network airflow models exists, where the most commonly used are COMIS, CONTAM, EnergyPlus, and ESP-r $[25,69]$.

Moreover, a study combining the analytical, empirical, and network models uses CONTAM to evaluate the influence of the location of air infiltration (or air leakages), on the global airflow rate estimated [47]. Here, this study evaluated the location of air infiltration by performing separate tests for accounting individually, the wind effects, and thermal buoyancy effects. Results showed that the location of the air-leakages has no apparent influence on the results given by the CONTAM software.

In cases where the indoor air movements due to a temperature difference can be approximated to a phenomenon named displacement ventilation, analytical models can be found in the literature for simple building geometries with a heat source at the bottom of the building. The authors in [71] developed modify two analytical models 


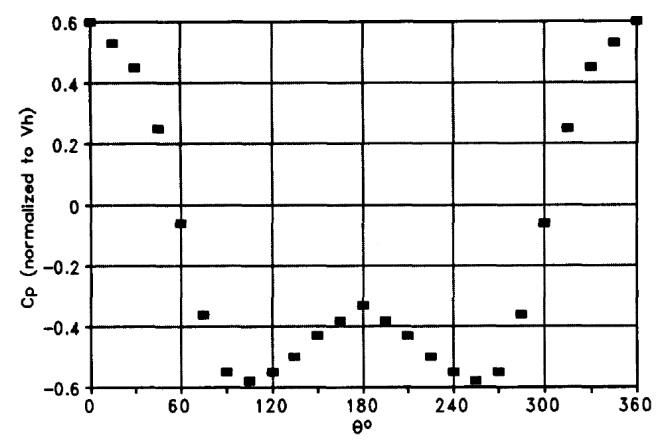

Figure 17 Averaged facade pressure coefficient as a function of azimuth angle [67]

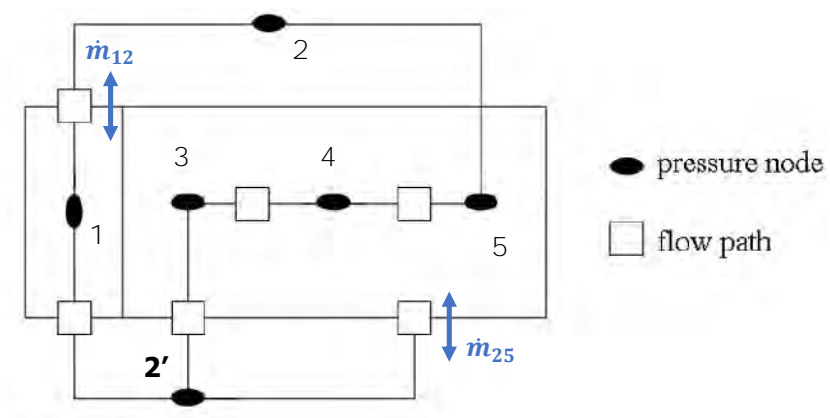

Source: Santamouris (1998)

Figure 19 Example of a network airflow modeling applied to a multi-zone building [32]

to study the transient natural displacement ventilation in a simple building geometry. These two models were compared with the Kaye and Hunt's model (KH), where the assumption of a well-mixed indoor air is made. Moreover, these three models are confronted with experimental data, where the two developed models (with a relative deviation of $4.2 \%$ and $4.6 \%$, respectivelyl had shown to perform better than the $\mathrm{KH}$ model.

Another analytical approach found in literature is the electrical analogy approach, which is also employed for network airflow paths, avoiding the use of the Newton-Raphson's method. This electrical analogy approach is based on an equivalent airflow resistance where the assumption that airflow paths are considered as capacitors [11], as shown in Figure 20. The equivalent airflow resistance of the example shown in Figure 20, results in the following Equation (22):

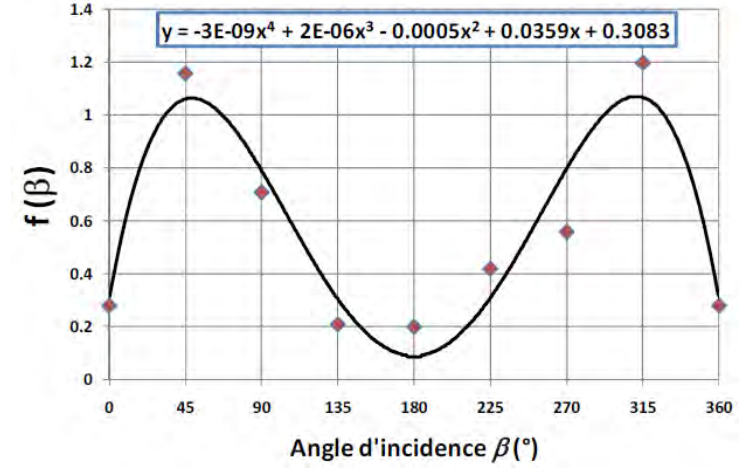

Figure 18 Fitted regression model over experimental data of a coefficient regarding wind effects as a function of the incident angle [68]

$$
\begin{aligned}
\left(C_{d} S_{e f f}\right)_{e q}^{2}= & \left\{\left[\left(C_{d} S_{e f f}\right)_{1}^{2} / /\left[\left(C_{d} S_{e f f}\right)_{2}^{2}+\right.\right.\right. \\
& \left.\left(C_{d} S_{e f f}\right)_{3}^{2}\right] / /\left(C_{d} S_{e f f}\right)_{4}^{2} / / \\
& \left\{\left(C_{d} S_{e f f}\right)_{5}^{2}+\left(C_{d} S_{e f f}\right)_{6}^{2}\right\} \quad\left[m^{2}\right] .
\end{aligned}
$$

in this Equation, the windows are assumed to be of the same type, and thus, to have the same discharge coefficient.

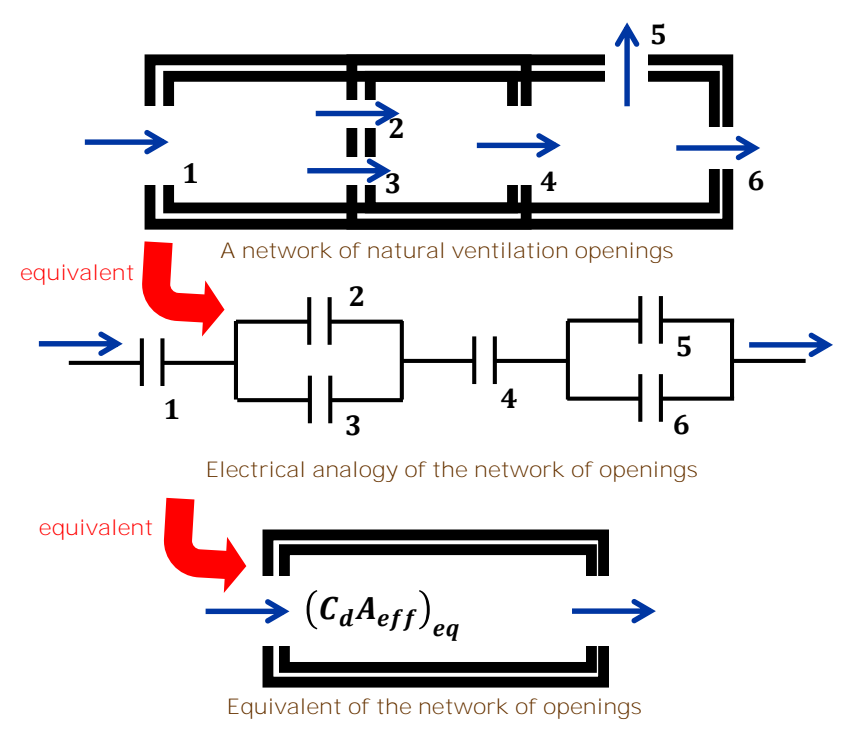

Figure 20 Example of an equivalent opposing resistance to airflow for a network of openings

An experimental study compared results from blower door experiments (using Equation (9)), and a model that uses this electrical analogy approach is presented in [45]. The airflow path network consisted of 10 openings distributed along the North and South facades, where the 
North-facing openings were of different sizes of those at the South facade. Here, the indoor air movements were assumed only to be driven by thermal buoyancy, and since only a night natural ventilation strategy was applied, the lower openings were considered as inlets, and the higher openings were considered as outlets. Results showed that a relative deviation of about $7 \%$ was obtained between theoretical and experimental results.

Finally, apart from the software mentioned before that allows us to solve the analytical models as the network airflow path models, software capable of performing integrated CFD simulations are Open studio, DesignBuilder, Envimet, and Comsol.

\section{Discussion}

We have covered the basics for comprehending the natural ventilation concept. We have briefly reviewed the experimental and modeling techniques already implemented for past researchers, in the estimation of the ventilation airflow rate due to the wind and thermal buoyancy effects. This literature review has allowed noticing that the location of the air-leakage/infiltrations must be analyzed attentively, to avoid overestimation or underestimation of the air-leakage rate.

The experimental techniques require heavy instrumentation (often expensivel of the openings in terms of airspeed and pressure measurements (local), being the ones that could lead to a better understanding of the phenomena involved in the ventilation process. The modeling techniques such as CFD require substantial computation time depending on the computer power and the models themselves. The other models, popular like the openings network, do not require as much computational time as the latter. The models based on empirical observations require knowledge of the airflow patterns within the building.

Regarding the experimental and modeling techniques for estimating the ventilation airflow rate, a limitation arises in their applicability depending on the following aspects in order of decreasing importance: The level of detail required in the study, funding availability, building geometry complexity (due to $C_{p}$ values), openings type (due to $C_{d}$ values), and openings distribution (due to the difficulty in determining the inlets and outlets).

The most suitable experimental technique seems to be the airtightness tests since it allows us to obtain empirical Equations relating the ventilation airflow directly to the pressure difference in the building for both cases: infiltrations (openings closed) and openings opened. Also, the location of the leakages can be identified without complications, and this technique has the potential to estimate in situ the airflow capacity and friction characteristics of the openings.

\section{Conclusion}

This work has covered the fundamentals for understanding the natural ventilation concept in buildings and the main three driven forces causing indoor air movements: wind effects, thermal buoyancy effects, and the concentration of contaminants and moisture. Mainly, this article focuses on the airflow estimation techniques implemented by former researchers, specifically the experimental techniques. Such experimental techniques reviewed include the blower door tests, direct air velocity, and pressure measurements, wind tunnel for scaled models, tracer gas decay method, and scale models with dimensional analysis. The modeling techniques briefly reviewed include empirical correlations and analytical approaches.

Concerning the experimental and modeling techniques for estimating the ventilation airflow rate, a limitation arises in their applicability strongly dependant on the level of detail required in the study and the funding availability. The adequate benefit-to-budget technique appears to be the blower door tests, since empirical Equations relating the airflow directly to the pressure difference in the building for both cases: infiltrations (openings closed) and openings opened, can be obtained. Also, the location of the leakages can be identified without complications, and this technique has the potential to estimate in situ the airflow capacity and friction characteristics of the openings.

\section{Declaration of Competing Interest}

We declared that we have no financial, professional and personal competing interests interfering with the work described in this manuscript.

\section{Acknowledgment}

The authors would like to thank the Technological University of Panama and the Faculty of Mechanical Engineering for their collaboration, together with an extended appreciation to the Sistema Nacional de Investigación (SNI). 


\section{Funding}

This work was supported by IFARHU, a Panamanian institution in charge of economic support for internal and external undergraduate and graduate scholarships.

\section{Author contributions}

M. Chen Austin: Writing - original draft; Formal analysis; Investigation. D. Mora: Formal analysis; Investigation. D. Bruneau: Conceptualization, Supervision, Funding aquisition. A. Sempey: Formal analysis, conceptualization.

\section{Available statement}

The authors confirm that the data supporting the findings of this study are available within the article [and/or] its supplementary materials.

\section{References}

[1] J. Araúz, D. Mora, and M. Chen Austin, "Impact of the Envelope Layout in the Thermal Behavior of Buildings in Panama: A Numerical Study," in 2019 7th International Engineering, Sciences and Technology Conference (IESTEC), Oct. 2019, pp. 209-214.

[2] M. Zune, L. Rodrigues, and M. Gillott, "Vernacular passive design in Myanmar housing for thermal comfort," Sustainable Cities and Society, vol. 54, p. 101992, Mar. 2020. [Online]. Available: https://linkinghub.elsevier.com/retrieve/pii/S2210670719335334

[3] D. Rayter, "Guía de aplicación de arquitectura bioclimática en locales educativos," Lima, Perú, p. 111, 2008.

[4] E. G. Castillo, E. Coronado, and 0. Osejo, "Anteproyecto Arquitectónico de un complejo habitacional con énfasis en criterios de Diseño Bioclimático aplicados a edificios de unidades habitacionales en el sector de Villa Fontana Norte; Municipio de Managua, Nicaragua." Ph.D. dissertation, Universidad Nacional de Ingenieria, 2014.

[5] "Introduction I IEA-EBC Annex 66," https://annex66.org/. [Online]. Available: https://annex66.org/

[6] "IEA EBC || Annex 79 || Occupant Behaviour-Centric Building Design and Operation," https://annex79.iea-ebc.org/. [Online]. Available: https://annex79.iea-ebc.org/

[7] C. Zürcher and T. Frank, Physique du bâtiment - Construction et énergie. vdf Hochschulverlag AG and der ETH Zürich, 2014.

[8] H. Zheng, F. Li, H. Cai, and K. Zhang, "Non-intrusive measurement method for the window opening behavior," Energy and Buildings, vol. 197, pp. 171-176, 2019. [Online]. Available: https://www. sciencedirect.com/science/article/pii/S0378778819300040

[9] Y. Chen, Z. Tong, H. Samuelson, W. Wu, and A. Malkawi, "Realizing natural ventilation potential through window control: The impact of occupant behavior," Energy Procedia, vol. 158, pp. 3215-3221, 2019. [Online]. Available: https://www.sciencedirect.com/science/article/ pii/S1876610219310562

[10] D. Mora, J. Araúz, and M. Chen Austin, "Towards nearly zero energy buildings in Panama through low-consumption techniques: A numerical study," in AIP Conference Proceedings, 2019, p. 2191.

[11] F. Allard, Natural ventilation in buildings: A design handbook. James and James - UK (Science publisher), 1998.

[12] A. Ricaud and I. Lokhat, Construire une maison à énergie positive. Dunod Paris, 2010.
[13] E. Solgi, Z. Hamedani, R. Fernando, H. Skates, and N. E. Orji, “A literature review of night ventilation strategies in buildings," Energy and Buildings, vol. 173, pp. 337 - 352, 2018. [Online]. Available: http: //www.sciencedirect.com/science/article/pii/S0378778818307850

[14] D. Bravo-Hidalgo, "Night air conditioning of buildings by external air ventilation," Revista Facultad de Ingeniería, vol. 27, no. 48, pp. 35-47, 2018.

[15] M. Palme, C. Carrasco, M. Ángel Gálvez, and L. Inostroza, “Natural Ventilation: A Mitigation Strategy to Reduce Overheating in Buildings under Urban Heat Island Effect in South American Cities," IOP Conference Series: Materials Science and Engineering, vol. 245, no. 7, 2017.

[16] G. Carpentier and J. Uyttenbroeck, "La ventilation des bâtiments en relation avec la consommation d'énergie pour le chauffage," Rapport III - Commission des communautés européennes, , 1978.

[17] D. Etheridge and P. Phillips, "The prediction of ventilation rates in houses and the implications for energy conservation," C.I.B. S17 Meeting - Holzkirchen, , 1977.

[18] S. J. Emmerich, W. S. Dols, and J. W. Axley, "Natural ventilation review and plan for design and analysis tools," National Institute of Standards and Technology (NIST), , 2001.

[19] A. Accili and J. Arias Hurtado, "Natural ventilation strategies for nearly - Zero Energy Sports Halls," 2016.

[20] A. Belleri, R. Lollini, and S. M. Dutton, "Natural ventilation design: An analysis of predicted and measured performance," Building and Environment, vol. 81, pp. 123 - 138, 2014. [Online]. Available: http: //www.sciencedirect.com/science/article/pii/S0360132314001954

[21] C.-A. Roulet, Santé et qualité de l'environnement intérieur dans les bâtiments. PPUR - Science et ingénierie de l'environnement, 2010.

[22] T. Kleiven, "Natural ventilation in buildings - architectural concepts, consequences and possibilities," Ph.D. dissertation, 2003, norwegian University of Science and Technology.

[23] B. Givoni, Man, Climate and Architecture, ser. Architectural Science Series. Applied Science Publ., 1976.

[24] J. D. A. Jr., Fundamentals of Aerodynamics, ser. Architectural Science Series. McGraw Hill - 5th edition, 2011.

[25] D. Cóstola, B. Blocken, and J. Hensen, "Overview of pressure coefficient data in building energy simulation and airflow network programs," Building and Environment, vol. 44, no. 10, pp. 2027 - 2036, 2009. [Online]. Available: http://www.sciencedirect.com/ science/article/pii/S0360132309000444

[26] R. Li, A. Pitts, and Y. Li, "Buoyancy-driven natural ventilation of a room with large opennings," in IBPSA 2007: Building Simulation, 2007.

[27] F. Flourentzou, J. V. der Maas, and C.-A. Roulet, "Natural ventilation for passive cooling: measurement of discharge coefficients," Energy and Buildings, vol. 27, pp. 283-292, 1998.

[28] K. Andersen, "Naturlig ventilation i erhvervsbygninger, by og byg," Statens Byggeforskningsinstitutt - Hørsholm, , 2002.

[29] K. Gtadyszewska-Fiedoruk and A. Gajewski, "Effect of wind on stack ventilation performance," Energy and Buildings, vol. 51, pp. 242 - 247, 2012. [Online]. Available: http://www.sciencedirect.com/ science/article/pii/S0378778812002629

[30] B. Wang, "Interaction between wind-driven and buoyancy-driven natural ventilation," in 13th Conference of International Building Performance Simulation Association - Chambéry France August 26-28, 2013.

[31] M. H. Sherman, "Estimation of infiltration from leakage and climate indicators," Energy and Building, vol. 10, pp. 81-86, 1987.

[32] C. Ghiaus and F. Allard, Natural Ventilation in the Urban Environment: Assessment and Design. Earthscan, 2005.

[33] A. Judet and B. Sesolis, Aéraulique : Principes de l'aéraulique appliqués au génie climatique. Collection des guides thématiques de l'AICVF, PYC édition, 1991.

[34] K. S. Hebbar, K. Sridhara, and P. A. Paranjpe, "Performance of conical jet nozzles in terms of discharge coefficient," Journal of the aeronautical society of India, vol. 22, no. 1, pp. 4-9, 1969.

[35] P. Heiselberg, K. Svidt, and P. V. Nielsen, "Characteristics of airflow from open windows," Building and Environment, vol. 36, no. 7, pp. 859 - 869. 2001, ventilation for Health and Substainable Environment. 
[Online]. Available: http://www.sciencedirect.com/science/article/ pii/S0360132301000129

[36] D. Costola and D. Etheridge, "Unsteady natural ventilation at model scale-flow reversal and discharge coefficients of a short stack and an orifice," Building and Environment, vol. 43, no. 9, pp. 1491 - 1506, 2008. [Online]. Available: http://www.sciencedirect.com/science/ article/pii/S0360132307001618

[37] R. Teppner, B. Langensteiner, W. Meile, G. Brenn, and S. Kerschbaumer, "Air change rates driven by the flow around and through a building storey with fully open or tilted windows: An experimental and numerical study," Energy and Buildings, vol. 76, pp. 640 - 653, 2014. [Online]. Available: http: //www.sciencedirect.com/science/article/pii/S0378778814002199

[38] A. V. Paassen, S. Liem, and B. Gröninger, "Control of night cooling with natural ventilation: Sensitivity analysis of control stratégies and vent openings," in 19th Annual AIVC Conference, Ventilation and cooling - Oslo, 28-30 septembre, 1998.

[39] M. Krzaczek, J. Florczuk, and J. Tejchman, “Field investigations of stack ventilation in a residential building with multiple chimneys and tilted window in cold climate," Energy and Buildings, vol. 103, pp. 48 $-61,2015$.

[40] M. Caciolo, "Analyse expérimentale et simulation de la ventilation naturelle mono-façade pour le rafraîchissement des immeubles de bureaux," Ph.D. dissertation, 2010, ecole nationale supérieure des mines de Paris.

[41] R. Pelletret, G. Liebecq, F. Allard, J. V. der Maas, , and F. Haghighat, "Modelling of large openings," in AIVC 21th Conference, Air Movement and Ventilation Control within Buildings - Ottawa Canada, 1991.

[42] ASHRAE, Handbook - Fundamentals. American Society of Heating, Refrigeration and Air-Conditioning Engineers, 2009.

[43] L. Stephan, "Modélisation de la ventilation naturelle pour l'optimisation du rafraîchissement passif des bâtiments," Ph.D. dissertation, 2010, université Savoie Mont Blanc.

[44] R. Jack, D. Loveday, D. Allinson, and K. Lomas, “Quantifying the effect of window opening on the measured heat loss of a test house," in International SEEDS Conference 2015: Sustainable Ecological Engineering Design for Society - Leeds Beckett University, 2015, pp. 183 - 196.

[45] M. C. Austin, D. Bruneau, A. Sempey, L. Mora, and A. Sommier, "Experimental study of a natural ventilation strategy in a full-scale enclosure under meteorological conditions: a buoyancy-driven approach," in 6th Engineering, Science and Technology Conference - Panama 2017 (ESTEC 2017), 2017, pp. 657 - 667. [Online]. Available: https://knepublishing.com/index.php/KnE-Engineering/ article/view/1469/3542

[46] M. C. Austin, A. Sempey, D. Bruneau, and L. Mora, "Influence des effets du vent et du tirage thermique sur le taux de renouvellement de l'air d'un bâtiment ventilé naturellement : estimations par simulation aéraulique directe et par validation expérimentale d'une modélisation thermique," in Conférence IBPSA France - Bordeaux, 2018, pp. 13 - 21. [Online]. Available: http://ibpsa.fr/index.php? option=com_jdownloads\& Itemid=53\&view=viewcategory\&catid $=81$

[47] M. Chen Austin, "On the coupling between natural ventilation and sensible energy charge and discharge in buildings : an experimental and modeling approach," phdthesis, Université de Bordeaux, Sep. 2018. [Online]. Available: https://tel.archives-ouvertes.fr/ tel-01932939

[48] P. K. Heiselberg, K. Svidt, and P. V. Nielsen, "Windows: measurements of air flow capacity," Indoor Environmental Engineering, vol. R0040, no. 115, 2000

[49] G. A. Faggianelli, "Rafraîchissement par la ventilation naturelle traversante des bâtiments en climat méditerranéen," Ph.D. dissertation, 2014, université de Corse - Pascal Paoli.

[50] G. Elshafei, A. Negm, M. Bady, M. Suzuki, and M. G. Ibrahim, "Numerical and experimental investigations of the impacts of window parameters on indoor natural ventilation in a residential building," Energy and Buildings, vol. 141, pp. 321-332, Apr. 2017. [Online]. Available: https://linkinghub.elsevier.com/retrieve/ pii/S0378778817306503

[51] M. C. Austin, D. Bruneau, A. Sempey, and L. Mora, "Statistical analysis of architectural features effects on indoor environmental conditions in a plus energy house prototype," in Passive and Low Energy Architecture (PLEA) - Hong Kong, December 2018, accepted as long paper.

[52] H. Gough, Z. Luo, C. Halios, M.-F. King, C. Noakes, C. Grimmond, J. Barlow, R. Hoxey, and A. Quinn, "Field measurement of natural ventilation rate in an idealised full-scale building located in a staggered urban array: Comparison between tracer gas and pressure-based methods," Building and Environment, vol. 137, pp. 246-256, Jun. 2018. [Online]. Available: https://linkinghub.elsevier. com/retrieve/pii/S0360132318301902

[53] H. L. Gough, J. F. Barlow, Z. Luo, M. F. King, C. H. Halios, and C. S. B. Grimmond, "Evaluating single-sided natural ventilation models against full-scale idealised measurements: Impact of wind direction and turbulence," Building and Environment, vol. 170, p. 106556, Mar. 2020. [Online]. Available: http://www.sciencedirect. com/science/article/pii/S0360132319307681

[54] T. S. Larsen, P. K. Heiselberg, and T. Sawachi, "Analysis and design of single-sided natural ventilation," in The 4th International Symposium on Heating, Ventilation and Air-Conditioning - China, vol. 1, 2003, pp. 159-163.

[55] R. Z. Freire, M. O. Abadie, and N. Mendes, "Single-sided natural ventilation driven by wind pressure and temperature difference," Energy and Buildings, vol. 62, pp. 222 - 229, 2013.

[56] H. Sacht, L. Bragança, M. Almeida, and R. Caram, "Study of Natural Ventilation in wind Tunnels and Influence of the Position of Ventilation Modules and Types of Grids on a Modular Façade System," Energy Procedia, vol. 96, pp. 953-964, Sep. 2016. [Online]. Available: http://www.sciencedirect.com/science/article/ pii/S1876610216308128

[57] K. Kosutova, T. van Hooff, C. Vanderwel, B. Blocken, and J. Hensen, "Cross-ventilation in a generic isolated building equipped with louvers: Wind-tunnel experiments and CFD simulations," Building and Environment, vol. 154, pp. 263-280, May 2019. [Online]. Available: http://www.sciencedirect.com/science/article/ pii/S0360132319301738

[58] N. Su, S. Peng, N. Hong, and J. Zhang, “Experimental and numerical evaluation of wind-driven natural ventilation and dust suppression effects of coal sheds with porous gables," Building and Environment, vol. 177, p. 106855, Jun. 2020. [Online]. Available: http: //www.sciencedirect.com/science/article/pii/S0360132320302146

[59] M. Bady, S. Kato, T. Takahashi, and H. Huang, "Experimental investigations of the indoor natural ventilation for different building configurations and incidences," Building and Environment, vol. 46, no. 1, pp. 65-74, Jan. 2011. [Online]. Available: http://www. sciencedirect.com/science/article/pii/S0360132310002064

[60] S. Van Buggenhout, A. Van Brecht, S. Eren Özcan, E. Vranken, W. Van Malcot, and D. Berckmans, "Influence of sampling positions on accuracy of tracer gas measurements in ventilated spaces," Biosystems Engineering, vol. 104, no. 2, pp. 216-223, Oct. 2009. [Online]. Available: https://linkinghub.elsevier.com/retrieve/ pii/S1537511009001500

[61] G. Remion, B. Moujalled, and M. El Mankibi, "Review of tracer gas-based methods for the characterization of natural ventilation performance: Comparative analysis of their accuracy," Building and Environment, vol. 160, p. 106180, Aug. 2019. [Online]. Available: http: //www.sciencedirect.com/science/article/pii/S0360132319303907

[62] G. Hunt and P. Linden, "The fluid mechanics of natural ventilation-displacement ventilation by buoyancy-driven flows assisted by wind," Building and Environment, vol. 34, pp. 707-720, 1999.

[63] G. Remion, B. Moujalled, and M. E. Mankibi, "Experimental characterization of the impact of unsteady airflows on tracer gas measurement," IOP Conference Series: Materials Science and Engineering, vol. 609, p. 032028, oct 2019. [Online]. Available: https://doi.org/10.1088\%2F1757-899x\%2F609\%2F3\%2F032028

[64] G. N. Walton, "Airflow and multiroom thermal analysis," ASHRAE transactions, vol. 88, pp. $78-91,1982$.

[65] M. Swami and S. Chandra, "Correlations for pressure distribution of buildings and calculation of natural-ventilation airflow," ASHRAE 
Transactions, vol. 94, no. 4, pp. $244-266,1988$.

[66] M. Grosso, "Wind pressure distribution around buildings: a parametrical model," Energy and Buildings, vol. 18, no. 2, pp. 101 - 131, 1992. [Online]. Available: http://www.sciencedirect.com/ science/article/pii/037877889290041E

[67] P. Rousseau and E. Mathews, "A new integrated design tool for naturally ventilated buildings," Energy and Buildings, vol. 23, no. 3, pp. 231 - 236, 1996, pLEA '94 International Conference. [Online]. Available: http://www.sciencedirect.com/science/article/ pii/0378778895009485

[68] T. Larsen and P. Heiselberg, "Single-sided natural ventilation driven by wind pressure and temperature difference," Energy and Building, vol. 40, no. 6, pp. 1031 - 1040, 2008.

[69] Z. J. Zhai, M. E. Mankibi, and A. Zoubir, "Review of natural ventilation models," Energy Procedia, vol. 78, pp. 2700 - 2705 , 2015, 6th International Building Physics Conference, IBPC 2015. [Online]. Available: http://www.sciencedirect.com/science/article/ pii/S1876610215020871

[70] Z. J. Zhai, M.-H. Johnson, M. E. Mankibi, and N. Stathopoulos, "Review of natural ventilation models," International Journal of Ventilation, vol. 15, no. 3-4, pp. 186-204, 2016. [Online]. Available: https://doi.org/10.1080/14733315.2016.1214390

[71] X. Yang, Y. Kang, and K. Zhong, "Theoretical predictions of transient natural displacement ventilation," Building Simulation, vol. 6, no. 2, pp. 165-171, Jun. 2013. [Online]. Available: http: //link.springer.com/10.1007/s12273-013-0098-7 